\title{
7
}

\section{Quick Response in a Continuous-Replenishment-Programme Based Manufacturer-Retailer Supply Chain}

\author{
Shu-Lu Hsu ${ }^{1}$ and Chih-Ming Lee ${ }^{2}$ \\ 1 Department of Management Information Systems, \\ National Chiayi University \\ ${ }^{2}$ Department of Business Administration, \\ Soochow University \\ Taiwan
}

\section{Introduction}

With the widespread concept of partnership in supply chain management, the traditional replenishment process is fast giving way to the Quick Response (QR) and Continuous Replenishment Programme (CRP). QR is a movement in industries to shorten the replenishment lead time which is critical to reduce inventory level and improve the levels of customer service. Wal-Mart, Seven-Eleven Japan, and many other retailers apply tremendous pressure on their suppliers to reduce the replenishment lead time (Chopra and Mendil 2007). CRP is an efficient replenishment initiative which focuses on removing excess inventory throughout the pipeline and synchronizes demand with production (EAN International 2000). In CRP, the inventory of retailer is planned, monitored, and replenished by the supplier on behalf of the consumers. To enable CRP, sales data and inventory level of the retailer must be provided to the supplier via Electronic Data Interchange (EDI) or other electronic means. Thus, to successfully implement CRP requires the supplier and the retailer to work in a cooperative manner based on mutual trust and joint gains.

The lead time is needed for several operations among trading parties, such as ordering, manufacturing, delivering, and handling. In practice, lead time can be shortened with extra crashing costs. Many researchers have studied the inventory decision incorporating lead time reduction under various assumptions. For example, Liao and Shyu (1991) first developed an inventory model in which lead time was the unique decision variable. BenDaya and Raouf (1994) extended the previous model by including both lead time and order quantity as decision variables. Pan and Yang (2002) and Pan and Hsiao (2005) considered lead time crashing cost as a function of both the order quantity and the reduced lead time. Since the reduction of lead time may involve with the vendor and the buyer to improve the related operations, a dyadic vendor-buyer viewpoint for shortening lead time is often suggested. For instance, Iyer and Bergen (1997) compare the profits of a single vendor and a single buyer supply chain before and after QR based on a newsboy inventory model. BenDaya and Hariga (2004), Ouyang et al. (2004), Chang et al. (2006), and Ouyang et al. (2007) 
investigated the decision of lead time reduction in a context of a single-vendor-singleretailer integrated inventory system, in which the possibility of stockout of the supplier was ignored.

The study of inventory decision of CRP based inventory systems was initiated by Goyal (1976) by presenting a joint economic lot-size model for a supplier and a retailer. Subsequently, many researchers investigated this issue under various assumptions. For example, Banerjee (1986) generalized the model of Goyal (1976) by incorporating a finite replenishment rate for the supplier. Goyal (1988) extended Banerjee's work by relaxing the lot-for-lot policy for the supplier and assumed that the supplier's lot size is an integral multiple of retailer's order quantity. Goyal and Srinivasan (1992) further extended the model by relaxing the assumption that the supplier can supply to the retailer only after completing the entire production lot. At the same time, Banerjee and Banerjee (1992) extended the study of integrated inventory control to a multiple-retailer case by considering that the supplier delivers items to several buyers at a coordinated common cycle time. Banerjee and Banerjee (1994) generalized their previous model by dealing with the normally distributed demand case and assuming a fixed shortage cost attributable to each stockout incident.

To understand the effects of QR on the CRP based supply chains, we build a formal model of lead time reduction and replenishment decisions for a supply chain consisting of a manufacturer and multiple retailers in which the inventory throughout the supply chain is managed in a CRP context. The model extends the work of Banerjee and Banerjee (1994) by including the ordering cost and adopting $\mathrm{QR}$ with the expenditure regarded as a function of the reduced lead time. In stead of explicitly estimating the shortage cost, a service level constraint (SLC) approach is applied to the problem for which may skirt the difficult practical issue of explicitly determining the shortage cost (Chen and Krass 2001). According to the definition in Ouyang and Chuang (2000), the service level in this study is measured by the expected fraction of demand met from inventory on hand in an inventory cycle. The objective of the model is to determine the common shipment cycle time and the replenishment lead time for the retailers, the manufacturer's production cycle time, and the target levels of replenishment for the manufacturer and each retailer so that the expected total system cost can be minimized under the service level constraint.

\section{Notations and assumptions}

To develop the proposed models, we adopt the following notation which is principally the same as that in Banerjee and Banerjee (1994):

$n=$ total number of retailers;

$d_{i} \quad=$ demand rate of retailer $i$, which follows a probability density function (p.d.f.) $f_{i}\left(d_{i}\right)$

with mean $D_{i}$ and variance $\sigma_{i}^{2}, i=1,2, \ldots, n$;

$h_{i} \quad=$ carrying cost per unit per year for retailer $i$ (\$/ unit/year);

$h_{v} \quad=$ carrying cost per unit per year for the manufacturer (\$/unit/year);

$l \quad=$ length of lead time for retailers (year), a decision variable;

$x_{i} \quad=$ demand during the protection period $(T+l)$ on retailer $i$, which has a p.d.f. $f_{i T+L}\left(x_{i}\right)$ with the mean $D_{i}(T+l)$ and the variance $\sigma_{i}^{2}(T+l)$; 
$y=$ demand during the production cycle time of $K T$ on manufacturer, which has a p.d.f. $g(y)$ with the mean $K T \sum_{i=1}^{n} D_{i}$ and the variance $K T \sum_{i=1}^{n} \sigma_{i}^{2}$;

$z_{i} \quad=$ safety factor for retailer $i$ with $z_{i} \geq 0$;

$z_{v} \quad=$ safety factor for the manufacturer with $z_{v} \geq 0$;

$a_{i} \quad=$ the threshold of retailer $i^{\prime}$ s service level, $0 \leq a_{i} \leq 1$;

$a_{v} \quad=$ the threshold of manufacturer's service level, $0 \leq a_{v} \leq 1$;

$A \quad=$ setup cost for the manufacturer (\$/per setup);

$C=$ common ordering cost shared by all retailers $(\$ /$ per order);

$C_{i} \quad=$ individual ordering cost for retailer $i$ (\$/per order);

$C_{r}(l) \quad=$ lead-time crashing cost per order;

$P \quad=$ production rate of manufacturer, which is a known constant;

$D \quad=\sum_{i=1}^{n} d_{i}$, total demand from all the retailers on the manufacturer per year, which has mean $\sum_{i=1}^{n} D_{i}$ and variance $\sum_{i=1}^{n} \sigma_{i}^{2}$. Note that, of necessity, $P>\sum_{i=1}^{n} D_{i}$;

$K=$ integral number of shipments to retailers per manufacturer's production cycle, which is a decision variable with $K \geq 1$;

$S_{i} \quad=$ replenish-up-to level after placing a new order for retailer $i$, a decision variable;

$S_{v} \quad=$ produce-up-to level after placing a new manufacture order for the manufacturer, a decision variable;

$T=$ common shipment cycle time to all retailers (year), a decision variable;

$E C_{i} \quad=$ the expected annual inventory cost for retailer $i$;

$E C_{v} \quad=$ the expected annual inventory cost for the manufacturer;

ETC = the expected annual total cost for the system.

The major assumptions made in this study are the following:

1. In the CRP context, the manufacturer plans, monitors, and replenishes the inventory of retailers based on the information of sales data and inventory level provided by all the retailers to minimize the expected annual total cost of the supply chain.

2. The demand rate of each retailer is independently distributed.

3. Each production lot of the manufacturer will be delivered in an integral number, $K$, of shipments to all retailers periodically.

4. The target level of replenishment of $S_{i}$ units for retailer $i$ is equal to the sum of retailer $i$ 's expected demand during the protection period, $D_{i}(T+l)$, and the safety stock, where safety stock $=z_{i} \sigma_{i} \sqrt{T+l}$.

5. The target level of production of $S_{v}$ units for the manufacturer is equal to the sum of manufacturer's expected demand during the production cycle, $K T \sum_{i=1}^{n} D_{i}$, and safety stock, where safety stock $=z_{v} \sqrt{K T \sum_{i=1}^{n} \sigma_{i}^{2}}$.

6. For each order, a common ordering cost $C$ is incurred to and shared by all retailers and an individual ordering $\operatorname{cost} C_{i}$ is incurred to the retailer $i$.

7. The manufacturer incurs a setup cost $A$ for each production run. 
8. The service level measures, i.e., fraction of demand met per cycle, for the retailer $i$ and for the manufacturer are defined as $1-\frac{E\left(x_{i}-S_{i}\right)^{+}}{D_{i}(T+l)}$ and $1-\frac{E\left(y-S_{v}\right)^{+}}{K T \sum_{i=1}^{n} D_{i}}$, respectively.

9. The expenditure for implementing $\mathrm{QR}$ is modeled as the lead-time crashing cost per order, $C_{r}(l)$, and is assumed to be a non-increasing stairstep function of $l$, such as:

$$
C_{r}(l)=\left\{\begin{array}{cc}
0 & l=l_{0}, \\
r_{1} & l_{1} \leq l<l_{0}, \\
\vdots & \vdots \\
r_{b} & l_{b} \leq l<l_{b-1},
\end{array}\right.
$$

where $l_{0}$ and $l_{b}$ represent the existing and the minimal length of lead times, respectively. This cost could be expenditure on equipment improvement, order expediting, or special shipping and handling.

\section{Model development and solution}

Figure 1 depicting the inventory time plots for a manufacturer and $n$ retailers, illustrates the CRP based inventory control system proposed in this work. For the retailer $i$, there is a target level of replenishment of $S_{i}$ units. For the manufacturer, there is a target level of production of $S_{v}$ units. Given a common shipment cycle time of $T$ years, the manufacturer produces a batch of item every KT years. After the Kth shipment cycle since the beginning of the last production cycle, the manufacturer begins the production of another lot $D T / P$ years prior to the next scheduled shipment time, as shown in Figure 1, which is illustrated the case of $K=3$. In order to cope with a stochastic demand, all of the trading parties carry safety stocks.

The demand during the protection period for retailer $i$ is assumed to be normally distributed with mean $D_{i}(T+l)$ and standard deviation $\sigma_{i} \sqrt{T+l}$. Then, the total demand from all retailers on the manufacturer during a production cycle of $K T$ is normally distributed with the mean $K T \sum_{i=1}^{n} D_{i}$ and the standard deviation $\sqrt{K T \sum_{i=1}^{n} \sigma_{i}^{2}}$. For the retailer $i$, with a cycle of $T$, a replenishment lead time of $l$, and a target level of $S_{i}$, the expected net inventory level just before receipt of an order is given by $S_{i}-D_{i} l-D_{i} T$ and the expected net inventory level immediately after the successive order is $S_{i}-D_{i} l$. Then, the average inventory over the cycle is approximated by $\frac{1}{2}\left[\left(S_{i}-D_{i} l-D_{i} T\right)+\left(S_{i}-D_{i} l\right)\right]$. According to the fourth assumption, the target levels of replenishments, $S_{i}$, is set as

$$
S_{i}=D_{i}(T+l)+z_{i} \sigma_{i} \sqrt{T+l} .
$$

So that the retailer i's expected annual carrying cost is

$$
\frac{h_{i}}{2}\left[\left(S_{i}-D_{i} l-D_{i} T\right)+\left(S_{i}-D_{i} l\right)\right]=h_{i}\left(S_{i}-D_{i} l-\frac{D_{i} T}{2}\right)=h_{i}\left(\frac{D_{i} T}{2}+z_{i} \sigma_{i} \sqrt{T+l}\right) .
$$


The annual individual ordering cost incurred to retailer $i$ is $C_{i} / T$. Then, the expected annual inventory cost for all retailers, consisting of common ordering cost, individual ordering cost, and carrying cost, is given by

$$
\sum_{i=1}^{n} E C_{i}=\frac{1}{T}\left(C+\sum_{i=1}^{n} C_{i}\right)+\sum_{i=1}^{n} h_{i}\left(\frac{D_{i} T}{2}+z_{i} \sigma_{i} \sqrt{T+l}\right) .
$$

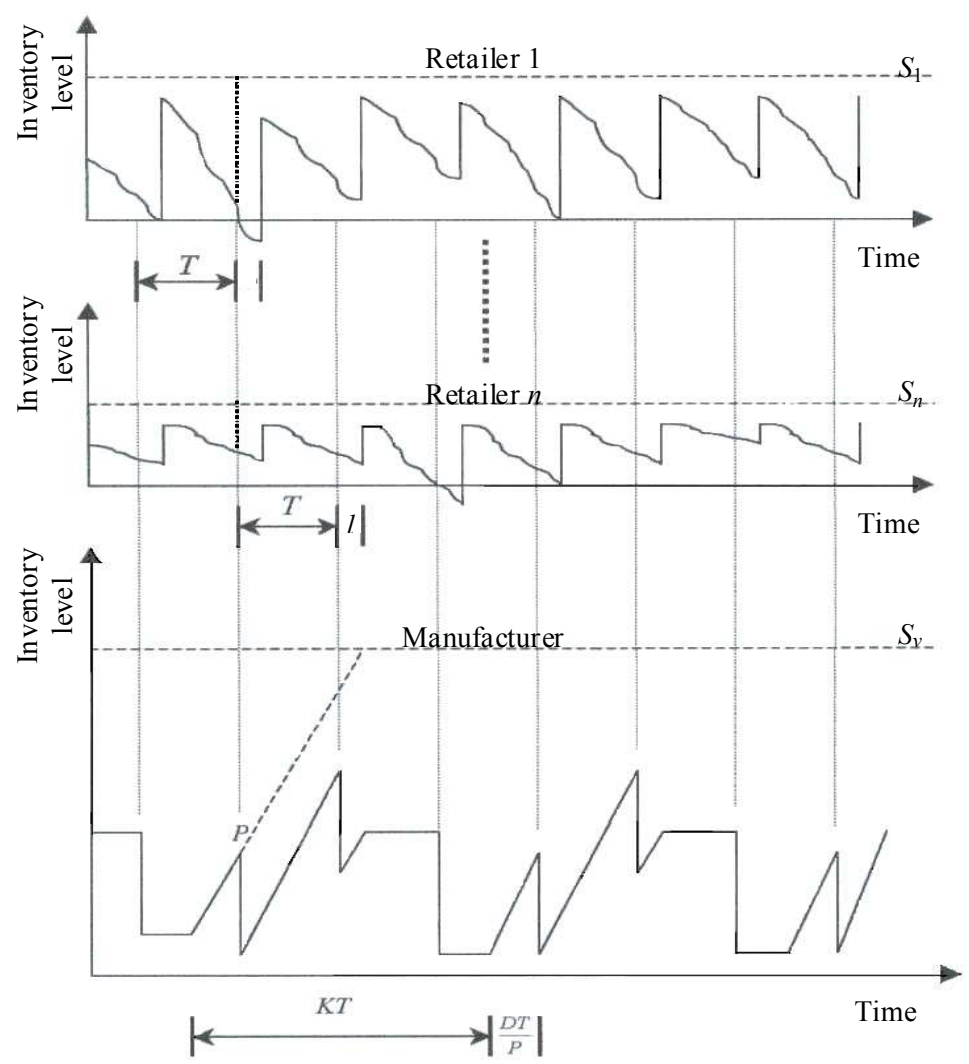

Fig. 1. Inventory levels for a manufacturer and multiple retailers under a coordinated common shipment cycle time

Based on the fifth assumption, the target levels of replenishments, $S_{v}$, is set as

$$
S_{v}=K T \sum_{i=1}^{n} D_{i}+z_{v} \sqrt{K T \sum_{i=1}^{n} \sigma_{i}^{2}} .
$$

According to Banerjee and Banerjee (1994) with Eq. (2), the manufacturer's average inventory can be derived as 


$$
\frac{\sum_{i=1}^{n} D_{i} T}{2}\left[\frac{\sum_{i=1}^{n} D_{i}}{P}(2-K)+K-1\right]+S_{v}-K T \sum_{i=1}^{n} D_{i}=\frac{\sum_{i=1}^{n} D_{i} T}{2}\left[K\left(1-\frac{\sum_{i=1}^{n} D_{i}}{P}\right)+\frac{2 \sum_{i=1}^{n} D_{i}}{P}-1\right]+z_{v} \sqrt{K T \sum_{i=1}^{n} \sigma_{i}^{2}}
$$

Then, the manufacturer's expected annual inventory cost is given by

$$
E C_{v}=\frac{A}{K T}+h_{v}\left\{\frac{\sum_{i=1}^{n} D_{i} T}{2}\left[K\left(1-\frac{\sum_{i=1}^{n} D_{i}}{P}\right)+\frac{2 \sum_{i=1}^{n} D_{i}}{P}-1\right]+z_{v} \sqrt{K T \sum_{i=1}^{n} \sigma_{i}^{2}}\right\}
$$

where the first term represents the average annual setup cost and the second term is the average carrying cost.

Based on the service level measure defined in Ouyang and Chuang (2000), the following service level constraints are specified:

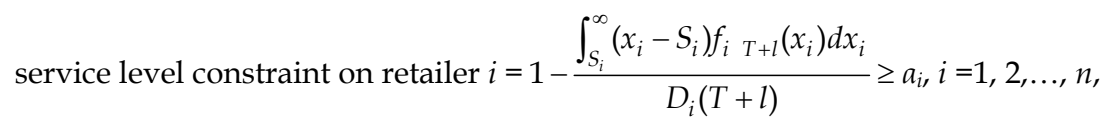

service level constraint on the manufacturer $=1-\frac{\int_{S_{v}}^{\infty}\left(y-S_{v}\right) g(y) d y}{K T \sum_{i=1}^{n} D_{i}} \geq a_{v}$.

As the demand is normally distributed, (3) and (4) can be rewritten as (see Appendix for proof):

service level constraint on retailer $i=\phi\left(z_{i}\right)-z_{i} \Phi\left(z_{i}\right)-\frac{\left(1-\alpha_{i}\right) D_{i} \sqrt{T+l}}{\sigma_{i}} \leq 0, i=1,2, \ldots, n$,

service level constraint on the manufacturer $=\phi\left(z_{v}\right)-z_{v} \Phi\left(z_{v}\right)-\frac{\left(1-\alpha_{v}\right) \sqrt{K T} \sum_{i=1}^{n} D_{i}}{\sqrt{\sum_{i=1}^{n} \sigma_{i}^{2}}} \leq 0$,

where $\phi(z)$ and $\Phi(z)$ represent the standard normal distribution and the complementary cumulative normal distribution function, respectively. The expected annual total cost for the system, comprising the expected annual inventory costs for all parties and the lead time crashing cost, is given by 


$$
\begin{gathered}
\operatorname{ETC}\left(K, T, l, \underline{z}, z_{v}\right)=\sum_{i=1}^{n} E C_{i}+E C_{v}+\frac{C_{r}(l)}{T} \\
=\frac{C+\sum_{i=1}^{n} C_{i}+\frac{A}{K}+C_{r}(l)}{T}+T\left\{\frac{\left.h_{v} \sum_{i=1}^{n} D_{i}\left[K\left(1-\frac{\left.\sum_{i=1}^{n} D_{i}\right)}{2}\right)+\frac{2 \sum_{i=1}^{n} D_{i}}{P}-1\right]+\sum_{i=1}^{n} \frac{D_{i} h_{i}}{2}\right\}}{+h_{v} z_{v} \sqrt{K T \sum_{i=1}^{n} \sigma_{i}^{2}}+\sum_{i=1}^{n} h_{i} z_{i} \sigma_{i} \sqrt{T+l},}\right.
\end{gathered}
$$

where the vector $\underline{z}=\left\{z_{1}, z_{2}, \ldots, z_{n}\right\}$. Then, the decision is to minimize $\operatorname{ETC}\left(K, T, l, \underline{z}, z_{v}\right)$ under the constraints (5) and (6).

In order to solve the nonlinear programming problem, the following propositions are needed.

Proposition 1. For any given $K, T, \underline{z}$, and $z_{v}$, the minimal ETC will occur at the end points of the interval $\left[l_{j+1}, l_{j}\right]$ when $C_{r}(l)$ is a stairstep function.

Proof:

As $C_{r}(l)$ is a stairstep function, $\frac{\partial^{2} C_{r}(l)}{\partial l^{2}}=0$ for any $l$ in a continuous interval $\left[l_{j+1}, l_{j}\right]$. The second derivative of (7) with respect to $l$ is equal to

$$
\frac{\partial^{2} E T C}{\partial l^{2}}=\frac{1}{T} \frac{\partial^{2} C_{r}(l)}{\partial l^{2}}-\frac{\sum_{i=1}^{n} h_{i} z_{i} \sigma_{i}}{4 \sqrt{(T+l)^{3}}}<0
$$

for any $l$ in a continuous interval $\left[l_{j+1}, l_{j}\right]$. Therefore, the proposition holds.

Proposition 2. For any fixed $K, l, \underline{z}$, and $z_{v}$, there is a unique optimal $T$ to ETC in (7).

Proof:

For any given $K, l, \underline{z}$, and $z_{v}$ in a continuous interval $\left[l_{j+1}, l_{j}\right]$, a necessary condition for a solution of $T$ to be optimal for (7) is

$$
\begin{aligned}
\frac{\partial E T C}{\partial T}= & \frac{C+\sum_{i=1}^{n} C_{i}+\frac{A}{K}+C_{r}(l)}{-T^{2}}+\frac{h_{v} \sum_{i=1}^{n} D_{i}}{2}\left[K\left(1-\frac{\sum_{i=1}^{n} D_{i}}{P}\right)+\frac{2 \sum_{i=1}^{n} D_{i}}{P}-1\right] \\
& +\frac{\sum_{i=1}^{n} D_{i} h_{i}}{2}+\frac{h_{v} z_{v} \sqrt{K \sum_{i=1}^{n} \sigma_{i}^{2}}}{2 \sqrt{T}}+\frac{\sum_{i=1}^{n} h_{i} z_{i} \sigma_{i}}{2 \sqrt{T+l}}=0
\end{aligned}
$$


The above equation can be rearranged as

$$
\begin{aligned}
\frac{C+\sum_{i=1}^{n} C_{i}+\frac{A}{K}+C_{r}(l)}{T^{2}} & =\frac{h_{v} \sum_{i=1}^{n} D_{i}\left[K\left(1-\frac{\sum_{i=1}^{n} D_{i}}{P}\right)+\frac{2 \sum_{i=1}^{n} D_{i}}{P}-1\right]}{2 \sqrt{T}}+\frac{\sum_{i=1}^{n} h_{i} z_{i} \sigma_{i}}{2 \sqrt{T+l}} \\
& +\sum_{i=1}^{n} \frac{D_{i} h_{i}}{2}+\frac{h_{v} z_{v} \sqrt{K \sum_{i=1}^{n} \sigma_{i}^{2}}}{2 \sqrt{T}}
\end{aligned}
$$

Let $T_{f}$ be the solution to (8). Then, the second derivative of (7) at $T_{f}$ satisfies

$$
\begin{aligned}
& \frac{\partial^{2} E T C}{\partial T^{2}\left(T_{f}\right)}=\frac{2\left(C+\sum_{i=1}^{n} C_{i}+\frac{A}{K}+C_{r}(l)\right)}{T_{f}^{3}}-\frac{h_{v} z_{v} \sqrt{K \sum_{i=1}^{n} \sigma_{i}^{2}}}{4 T_{f}^{3 / 2}}-\frac{\sum_{i=1}^{n} h_{i} z_{i} \sigma_{i}}{4\left(T_{f}+l\right)^{3 / 2}} \\
& =\frac{2}{T_{f}}\left\{\frac{h_{v} \sum_{i=1}^{n} D_{i}}{2}\left[K\left(1-\frac{\sum_{i=1}^{n} D_{i}}{P}\right)+\frac{2 \sum_{i=1}^{n} D_{i}}{P}-1\right]+\sum_{i=1}^{n} \frac{D_{i} h_{i}}{2}+\frac{h_{v} z_{v} \sqrt{K \sum_{i=1}^{n} \sigma_{i}^{2}}}{2 \sqrt{T_{f}}}+\frac{\sum_{i=1}^{n} h_{i} z_{i} \sigma_{i}}{2 \sqrt{T_{f}+l}}\right\} \\
& -\frac{h_{v} z_{v} \sqrt{K \sum_{i=1}^{n} \sigma_{i}^{2}}}{4 T_{f}^{3 / 2}}-\frac{\sum_{i=1}^{n} h_{i} z_{i} \sigma_{i}}{4\left(T_{f}+l\right)^{3 / 2}} \\
& =\frac{h_{v} \sum_{i=1}^{n} D_{i}}{T_{f}}\left[K\left(1-\frac{\sum_{i=1}^{n} D_{i}}{P}\right)+\frac{2 \sum_{i=1}^{n} D_{i}}{P}-1\right]+\sum_{i=1}^{n} \frac{D_{i} h_{i}}{T_{f}}+\frac{3 h_{v} z_{v} \sqrt{K \sum_{i=1}^{n} \sigma_{i}^{2}}}{4 T_{f} \sqrt{T_{f}}}+\frac{\left(3 T_{f}+4 l\right) \sum_{i=1}^{n} h_{i} z_{i} \sigma_{i}}{T_{f}\left(T_{f}+l\right)^{3 / 2}}>0 .
\end{aligned}
$$

That is, the second derivative of ETC at each $T_{f}$ is positive. The result implies that, for given $K, l, \underline{z}$, and $z_{v}$, an only solution for $T$, corresponding to the minimum of $E T C$, can be derived from (8). This completes the proof.

Proposition 3. For any given $K, T$, and $l$ in a continuous interval $\left[l_{j+1}, l_{j}\right]$, the boundary solution for $\underline{z}$ and $z_{v}$ derived from (5) and (6) is the optimal solution to this nonlinear programming problem. 


\section{Proof:}

By using the method of Lagrange multipliers, the problem can be transformed into

$$
\begin{gathered}
\operatorname{ETC}\left(K, T, l, \underline{z}, z_{v}, \underline{\lambda}, \underline{s}\right)=\frac{C+\sum_{i=1}^{n} C_{i}+\frac{A}{K}+C_{r}(l)}{T}+T\left\{\frac{h_{v} \sum_{i=1}^{n} D_{i}}{2}\left[K\left(1-\frac{\sum_{i=1}^{n} D_{i}}{P}\right)+\frac{2 \sum_{i=1}^{n} D_{i}}{P}-1\right]+\sum_{i=1}^{n} \frac{D_{i} h_{i}}{2}\right\} \\
+h_{v} z_{v} \sqrt{K T \sum_{i=1}^{n} \sigma_{i}^{2}}+\sum_{i=1}^{n} h_{i} z_{i} \sigma_{i} \sqrt{T+l}+\sum_{i=1}^{n} \lambda_{i}\left[\phi\left(z_{i}\right)-z_{i} \Phi\left(z_{i}\right)-\frac{\left(1-\alpha_{i}\right) D_{i} \sqrt{T+l}}{\sigma_{i}}+s_{i}^{2}\right] \\
+\lambda_{v}\left[\phi\left(z_{v}\right)-z_{v} \Phi\left(z_{v}\right)-\frac{\left(1-\alpha_{v}\right) \sqrt{K T} \sum_{i=1}^{n} D_{i}}{\sqrt{\sum_{i=1}^{n} \sigma_{i}^{2}}}+s_{v}^{2}\right]
\end{gathered}
$$

where $\underline{\lambda}$ is a vector of Lagrange multipliers with $\underline{\lambda}=\left\{\lambda_{1}, \lambda_{2}, \ldots, \lambda_{n}, \lambda_{v}\right\} \geq 0$, and $\underline{s}$ is a vector of slack variables with $\underline{s}=\left\{s_{1}{ }^{2}, s_{2}{ }^{2}, \ldots, s_{n}{ }^{2}, s_{v}{ }^{2}\right\}$. According to Kuhn-Tucker theorem (Taha, 2002), for any given $l$ in a continuous interval $\left[l_{j+1}, l_{j}\right]$, it can be shown that $\underline{s}=\{0,0, \ldots, 0\}$ is a necessary condition for a solution in (9) to be optimal. Then, for any given $l$ in a continuous interval $\left[l_{j+1}, l_{j}\right]$, the necessary conditions for (9) to be minimized are

$$
\begin{gathered}
\frac{\partial E T C}{\partial z_{i}}=h_{i} \sigma_{i} \sqrt{T+l}-\lambda_{i} \Phi\left(z_{i}\right)=0, i=1,2, . ., n, \\
\frac{\partial E T C}{\partial z_{v}}=h_{v} \sqrt{K T \sum_{i=1}^{n} \sigma_{i}^{2}}-\lambda_{v} \Phi\left(z_{v}\right)=0, \\
\frac{\partial E T C}{\partial \lambda_{i}}=\phi\left(z_{i}\right)-z_{i} \Phi\left(z_{i}\right)-\left(1-\alpha_{i}\right) D_{i} \frac{\sqrt{T+l}}{\sigma_{i}}=0, \\
\frac{\partial E T C}{\lambda_{v}}=\phi\left(z_{v}\right)-z_{v} \Phi\left(z_{v}\right)-\frac{\left(1-\alpha_{v}\right) \sqrt{K T} \sum_{i=1}^{n} D_{i}}{\sqrt{\sum_{i=1}^{n} \sigma_{i}^{2}}}=0,
\end{gathered}
$$

From (10) and (11), we have

$$
\lambda_{i}^{*}\left(z_{i}\right)=\frac{h_{i} \sigma_{i} \sqrt{T+l}}{\Phi\left(z_{i}\right)}>0, i=1,2, \ldots, n \text {, and } \lambda_{v}^{*}\left(z_{v}\right)=\frac{h_{v} \sqrt{K T \sum_{i=1}^{n} \sigma_{i}^{2}}}{\Phi\left(z_{v}\right)}>0 .
$$


Therefore, constraints (5) and (6) are binding. In addition, $\frac{\partial^{2} E T C}{\partial z_{i}^{2}}=\lambda_{i} \phi\left(z_{i}\right)>0(i=1,2, \ldots, n$, $m$ ), then the $\underline{z}$ and $z_{v}$ derived from (12) and (13) (i.e., the boundary solutions to (5) and (6)) are optimal to (9) with given $K, T$, and $l$.

Based on the above propositions, the optimal solution for $K, T, l, \underline{S}$, and $S_{v}$ to this nonlinear programming problem can be obtained by the following algorithm:

\section{Algorithm}

10. Set $K=1$.

11. Find $\operatorname{ETC}^{*}\left(K, l_{j} \mid j=0,1, \ldots, b\right)$

2.1 Let $j=0$

2.2 Set $l=l_{j} . z_{i}(i=1,2, \ldots, n)=0$, and $z_{v}=0$.

2.3 Compute $T^{*}$ by substituting $K, l_{j}, \underline{z}$ and $z_{v}$ into (8). Set $T_{k j}=T^{*}$.

2.4 Compute $\underline{z}^{*}$ by substituting $l_{j}$ and $T_{k j}$ into (12) and compute $z_{v}^{*}$ by substituting $K$ and $T_{k j}$ into (13).

2.5 Compute $T^{*}$ by substituting $K, l_{j}, \underline{z}^{*}$, and $z_{v}^{*}$ into (8).

2.6 If $T^{*}=T_{k j}$, go to step 2.7; otherwise, set $T_{k j}=T^{*}$ and go to step 2.4.

2.7 Set $T^{*}\left(K, l_{j}\right)=T_{k j}, \underline{z}^{*}\left(K, l_{j}\right)=\underline{z}^{*}$, and $z_{v}^{*}\left(K, l_{j}\right)=z_{v}^{*}$. Compute $E T C^{*}\left(K, l_{j}\right)$ by substituting $K, l_{j}, T^{*}\left(K, l_{j}\right), \underline{z}^{*}\left(K, l_{j}\right)$, and $z_{v}^{*}\left(K, l_{j}\right)$ into $(7)$.

2.8 Let $j=j+1$ and go back to step 2.2 until $j=b$.

12. Set $\operatorname{ETC}(K, l)=\operatorname{Min}\left[\operatorname{ETC}\left(K, l_{j}\right) \mid j=0,1, \ldots, b\right]$.

13. If $K=1$, set $E T C_{s}=\operatorname{ETC}(K, l), K=K+1, z_{i}(i=1,2, \ldots, n)=0, z_{v}=0$ and go back to step 2; otherwise go to step 5 .

14. If $\operatorname{ETC}(K, l)<E T C_{s}$, let $E T C_{s}=E T C(K, l), K=K+1, z_{i}(i=1,2, \ldots, n)=0, z_{v}=0$, and go back to step 2; otherwise let $E T C^{*}=E T C_{s}$ along with the corresponding values of $K$ and $l$ being the value of $K^{*}$ and $l^{*}$, respectively.

15. Find $T^{*}$ from (8) with the obtained $K^{*}$ and $l^{*}$. Find $z^{*}$ from (12) and $z_{v}^{*}$ from (13) with the obtained $K^{*}, l^{*}$, and $T^{*}$. Find $\underline{S}^{*}$ from (1) and $S_{v}^{*}$ from (2) with the obtained $K^{*}, l^{*}, T^{*}, \underline{z}^{*}$, and $z_{v}^{*}$. Output the values of $K^{*}, l^{*}, T^{*}, \underline{S}^{*}, S_{v}^{*}, E T C^{*}$ and Stop.

\section{Computer implementation}

The algorithm proposed in Section 3 has been implemented as a decision support system on a personal computer in which Intel Pentium D 2.8 GHz CPU with 1024 MB RAM inside it. Visual Basic 2005 is utilized as the software platform to develop the decision support system. Figure 2 shows the window to input the numbers of retailers, e.g., $n=3$ in this case, and steps of the lead-time crashing cost function, e.g., three steps in this case, involved in the replenishment and lead time reduction decisions. Once the decision maker inputs the numbers, a window to specify the relevant parameters will be displayed as shown in Figure 2. If all of the relevant parameters are input for the system, the decision maker then clicks the label "Find Solution" to select the lead time policy and to set the options of output. Figure 3 illustrates the result that the system derives the solution in which $K^{*}=2, l^{*}=0.005$ years, $T^{*}=0.0709$ years, $S_{1}^{*}=708, S_{2}^{*}=760, S_{3}^{*}=1276, S_{v}^{*}=3574$, and $E T C^{*}=\$ 19455.5$ for the case of implementing QR (representing by the controllable lead time option) after the 
Quick Response in

\begin{tabular}{|c|c|c|c|c|c|}
\hline \multicolumn{6}{|c|}{ Decision Support System for Coordinated Replenishment } \\
\hline \multicolumn{2}{|c|}{ Input Parameters } & \multicolumn{2}{|c|}{ Find Solution } & \multicolumn{2}{|c|}{ What-if Analysis } \\
\hline \multicolumn{6}{|c|}{ Input the number of retailers: } \\
\hline \multicolumn{4}{|c|}{ Input the number of steps for lead-time crashing cost function: 3} & \multicolumn{2}{|l|}{ Enter } \\
\hline \multicolumn{6}{|c|}{ Input parameters: } \\
\hline \multicolumn{6}{|l|}{ Manufacturer: } \\
\hline $\begin{array}{l}\text { Production } \\
\text { rate }\end{array}$ & $\begin{array}{l}\text { Setup } \\
\text { cost }\end{array}$ & $\begin{array}{l}\text { Carrying cost } \\
\text { rate }\end{array}$ & $\begin{array}{c}\text { Minimal } \\
\text { service level }\end{array}$ & & \\
\hline 28000 & 200 & 3 & 0.99 & & \\
\hline Retailers & $\begin{array}{l}\text { Demand } \\
\text { rate }\end{array}$ & $\begin{array}{l}\text { Standard deviation } \\
\text { of demand rate }\end{array}$ & $\begin{array}{l}\text { Minor order } \\
\text { cost }\end{array}$ & $\begin{array}{l}\text { Carrying cost } \\
\text { rate }\end{array}$ & $\begin{array}{c}\text { Minimal } \\
\text { service level }\end{array}$ \\
\hline Retailers 1 & 6000 & 600 & 100 & 5 & 0.99 \\
\hline Retailers2 & 5000 & 800 & 150 & 4 & 0.99 \\
\hline Retailers3 & 10000 & 900 & 80 & 4.5 & 0.99 \\
\hline
\end{tabular}

Major order cost: 100

Parameters of lead-time cashing cost:
$1_{0}: \underline{0.02}$
$\mathbf{1}_{1}: \underline{0.01} \quad \mathbf{1}_{2}: \underline{0.005}$
$\mathbf{1}_{3}: \underline{0.002}$
(in decreasing order)
Enter
Clear
$\mathrm{Cr}_{\mathbf{1}}: 5 \quad \mathrm{Cr}_{\mathbf{2}}: 11$
$\mathrm{Cr}_{3}: 18$
(in increasing order)

Fig. 2. The system window to input parameters

\begin{tabular}{|c|c|c|}
\hline \multicolumn{3}{|c|}{ 鷗Decision Support System for Coordinated Replenishment } \\
\hline Input Parameters & Find Solution & \\
\hline \multirow{9}{*}{$\begin{array}{l}\text { Select Lead Time Policy: } \\
\text { Controllable lead time } \\
C \text { Constant lead time }\end{array}$} & Output the Solution: & \\
\hline & F Number of Shipments per Production Cycle & \\
\hline & F Lead Time & \\
\hline & F Shipments Cycle Time & \\
\hline & $\sqrt{V}$ Replenish-up-to Level & \\
\hline & $\sqrt{V}$ Total System Cost & \\
\hline & $\Gamma$ Total Cost of Manufacturer & \\
\hline & $\Gamma$ Total Cost of Retailers & \\
\hline & $\sqrt{V}$ Benefit of Lead-time & Perform \\
\hline \multicolumn{3}{|l|}{${ }^{\star \star \star}$ The Solution ${ }^{\star \star \star}$} \\
\hline $\begin{array}{l}\mathrm{K}^{*}=2 \\
1^{*}=0.005 \\
\mathrm{~T}^{*}=0.0709 \\
\mathrm{~S}_{1}{ }^{*}=708 \\
\mathrm{~S}_{2}{ }^{*}=760 \\
\mathrm{~S}_{3}{ }^{*}=1276 \\
\mathrm{~S}_{\mathrm{V}}{ }^{*}=3574 \\
\mathrm{ETC}^{*}=19455.5 \\
\text { Saving }=143(0.73 \%)\end{array}$ & & \\
\hline
\end{tabular}

Fig. 3. The replenishment and lead time reduction decisions under CRP provided by the decision support system 


\begin{tabular}{|c|c|c|}
\hline 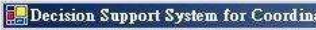 & & $-[0 \mid[|x|$ \\
\hline Input Parameters & What-if Analy & \\
\hline \multirow{9}{*}{$\begin{array}{l}\text { Select Lead Time Policy: } \\
\text { C Controllable lead time } \\
\text { c Constant lead time }\end{array}$} & Output the Solution: & \\
\hline & IV Number of Shipments per Production Cycle & \\
\hline & $\Gamma$ Lead Time & \\
\hline & $\sqrt{v}$ Shipments Cycle Time & \\
\hline & V Replenish-up-to Level & \\
\hline & $\sqrt{ }$ Total System Cost & \\
\hline & $\Gamma$ Total Cost of Manufacturer & \\
\hline & $\Gamma$ Total Cost of Retailers & \\
\hline & $\Gamma$ Benefit of Lead-time & Perform \\
\hline \multicolumn{3}{|l|}{ 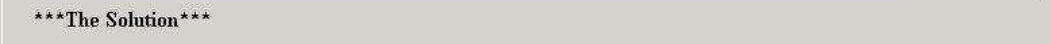 } \\
\hline $\begin{array}{l}\mathrm{K}^{*}=2 \\
\mathrm{I}^{*}=0.02 \\
\mathrm{~T}^{*}=0.0711 \\
\mathrm{~S}_{1}{ }^{*}=816 \\
\mathrm{~S}_{2}{ }^{*}=863 \\
\mathrm{~S}_{3}{ }^{*}=1302 \\
\mathrm{~Sv}^{*}=3583 \\
\mathrm{ETC}^{*}=19598.5\end{array}$ & & \\
\hline
\end{tabular}

Fig. 4. The coordinated replenishment decision under CRP provided by the decision support system

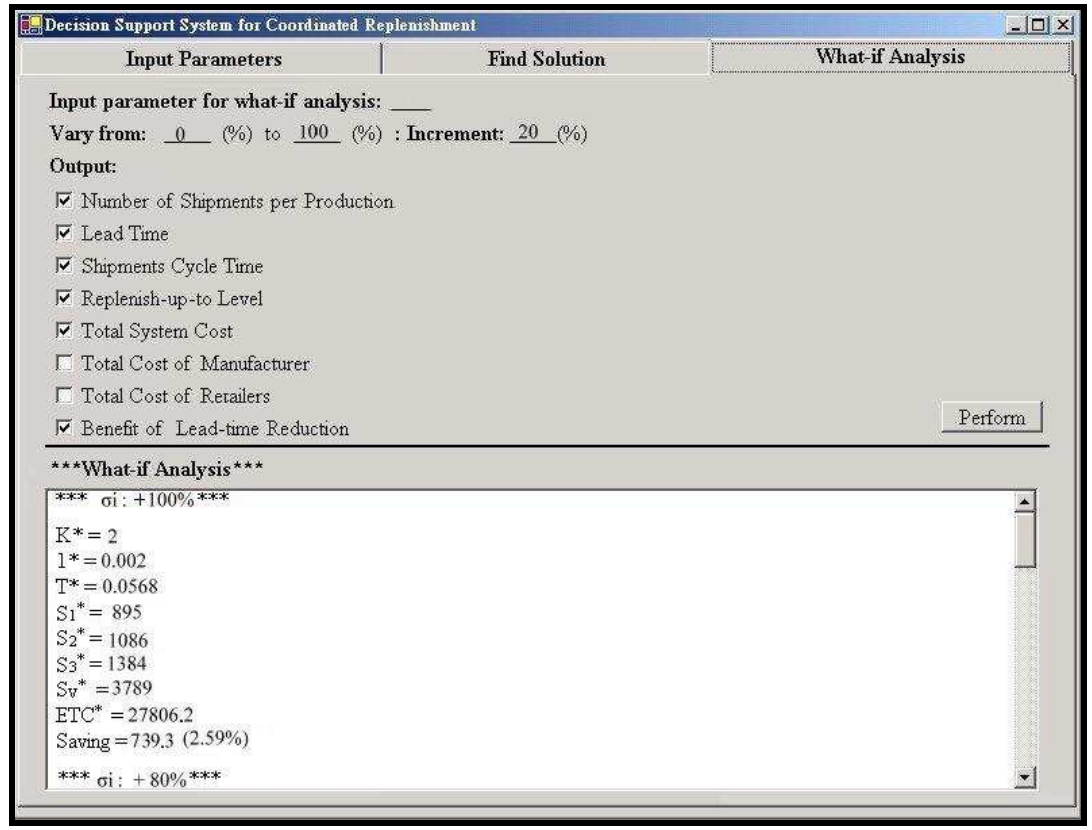

Fig. 5. The "what-if analysis" function of the decision support system 
decision maker clicks "Perform". From the value of "Saving", the benefit derived from implementing QR can be learned. As shown in Figure 4, the system also provides the inventory decision before $\mathrm{QR}$ (represented by the constant lead time option). One advantage of the system is that the decision maker can learn the sensitivity of replenishment and lead time decisions and the expected annual total cost of the chain by specifying the parameter with the variation range in the Window of "What-if Analysis". Figure 5 illustrates the output of the what-if analysis of $K^{*}, l^{*}, T^{*}, \underline{S}^{*}, S_{v}^{*}, E T C^{*}$, and the cost saving after QR against the variation of standard deviation of demand.

\begin{tabular}{|c|c|c|c|c|c|c|c|c|c|c|c|c|}
\hline & & $K^{*}$ & $T^{*}$ & $l^{*}$ & $S_{1}^{*}$ & $S_{2}^{*}$ & $S_{3}^{*}$ & $S_{v}^{*}$ & $E^{2} C^{*}$ & $K_{0}{ }^{a}$ & $T_{0} \mathrm{a}^{\mathrm{a}}$ & $\Delta E T C(\%)^{\mathrm{b}}$ \\
\hline \multicolumn{2}{|c|}{ Base example } & 2 & 0.0709 & 0.005 & 708 & 760 & 1276 & 3574 & 19455.3 & 2 & 0.0711 & 0.73 \\
\hline $\begin{array}{c}\sigma_{i} \\
(i=1,2,3)\end{array}$ & $+100 \%$ & 2 & 0.0568 & 0.002 & 895 & 1086 & 1384 & 3789 & 27806.2 & 2 & 0.0577 & 2.59 \\
\hline$P$ & $+100 \%$ & 1 & 0.0877 & 0.005 & 827 & 874 & 1320 & 2357 & 18822.3 & 1 & 0.0880 & 0.71 \\
\hline C & $+100 \%$ & 2 & 0.0779 & 0.005 & 758 & 808 & 1208 & 3885 & 20799.7 & 2 & 0.0781 & 0.67 \\
\hline $\begin{array}{c}C_{i} \\
(i=1,2,3)\end{array}$ & $+100 \%$ & 1 & 0.1024 & 0.005 & 930 & 970 & 1488 & 2691 & 23410.0 & 1 & 0.1027 & 0.54 \\
\hline$A$ & $+100 \%$ & 3 & 0.0705 & 0.005 & 705 & 757 & 1291 & 5108 & 20696.8 & 2 & 0.0781 & 1.16 \\
\hline $\begin{array}{c}h_{i} \\
(i=1,2,3)\end{array}$ & $+100 \%$ & 3 & 0.0507 & 0.005 & 560 & 616 & 886 & 3803 & 26567.3 & 3 & 0.0513 & 1.88 \\
\hline$h_{v}$ & $+100 \%$ & 1 & 0.0704 & 0.005 & 704 & 756 & 1120 & 1958 & 23078.6 & 1 & 0.0705 & 0.62 \\
\hline $\begin{array}{c}1-a_{i} \\
(i=1,2,3)\end{array}$ & $+100 \%$ & 2 & 0.0733 & 0.01 & 705 & 741 & 1128 & 3681 & 18548.2 & 2 & 0.0735 & 0.32 \\
\hline $1-a_{v}$ & $+100 \%$ & 2 & 0.0727 & 0.005 & 721 & 772 & 1147 & 3467 & 18897.2 & 2 & 0.0728 & 0.75 \\
\hline
\end{tabular}

a: $K_{0}$ and $T_{0}$ represent the optimal $K$ and $T$, respectively, before $Q R$ is implemented.

b: $\triangle E T C(\%)=\left(1-E T C^{*} / E T C_{0}\right) \times 100 \%$, where $E T C_{0}$ represents the optimal $E T C$ before $\mathrm{QR}$ is implemented.

Table 1. Sensitivity analysis for parameters

The sensitivity of the optimal solution has been further examined by conducting several numerical experiments. The results are illustrated by a base case and are shown in Table 1 . Some findings are summarized as follows:

1. The amount of $\triangle E T C(\%)$ measures the improvement rate of expected annual total system cost after implementing QR. The behavior of $\triangle E T C(\%)$ reveals that the supply chain may benefit from shortening the replenishment lead time.

2. The value of $\triangle E T C(\%)$ is especially sensitive to the variation of $\sigma_{i}$ or $h_{i}$. As $\sigma_{i}$ or $h_{i}$ increases, the value of $\triangle E T C(\%)$ increases. The results mean that the return of investment in QR is especially significant for a system with high uncertainty in demand or with high carrying costs incurred to the retailers.

3. The common shipment cycle time is more sensitive to the variance of demand, the variation of manufacturer's production rate, the individual ordering cost, and the retailer's carrying cost.

4. The shipment cycle time, $T^{*}$, will be reduced after implementing $Q R$ in which the replenishment lead time for retailers has been shortened. Moreover, the target levels of 
replenishments for the manufacturer and the retailers may become lower after bringing QR into practice.

5. The number of shipments per production cycle, $K^{*}$, after implementing QR is always no less than that before implementing QR. When the values of $K$ for the two situations are equal, the optimal shipment cycle time, $T^{*}$ as well as the protection period, $T^{*}+l^{*}$, after $\mathrm{QR}$ is always no large than those before QR. The result implies that under a fixed number of shipments during a production cycle, the protection period for the retailer will be reduced after implementing QR.

6. The increase of production rate will result in a longer shipment cycle time and higher target levels of replenishments for the retailers. In contrast, as the value of $P$ increases, the number of shipment per production cycle and the target level of production for the manufacturer will become smaller.

7. When the ordering cost increases, the shipment cycle time and the target levels of replenishments for each party will increase.

8. The value of $a_{i}$ specifies the minimal fraction of demand met per cycle for the retailer and directly relates with the length of protection period $(T+l)$. It can be found that the amount of $\triangle E T C(\%)$ decreases as the retailer's maximal fraction of demand unfilled per cycle increases. The result implies that the benefit from implementing $Q R$ is significantly related to the retailer's service level threshold and the benefit is substantial for a supply chain requesting a high customer service level.

9. The numerical example shows that as $1-a_{v}$ increases from $1 \%$ to $2 \%$, the length of common shipment cycle time increases by $2.54 \%$ (from 0.0709 to 0.0727 ) but the lead time is unaffected. The result implies that the effect of manufacturer's service level threshold is more significant on the common shipment cycle time than on the reduction of lead time.

\section{Conclusions}

Speed, service, and supply chain management have been core capabilities for business competition. The reduction of overall system response time with a satisfied service level has received a great deal of attention from researchers and practitioners. In this study, we investigated the effect of investing in QR on a CRP based supply chain where a manufacturer produces and delivers items to multiple retailers at a coordinated common cycle time with the minimized expected total system cost and satisfied service levels. Extending the work of Banerjee and Banerjee (1994) by involving ordering costs and the reducible replenishment lead time, a model and an algorithm are proposed to simultaneously determine the optimal shipment cycle time, target levels of replenishments, lead time, and number of shipments pre production cycle under service level constraints for the supply chain.

A numerical experiment along with sensitivity analysis was performed and the results explain the effect of QR on the replenishment decisions and the total system cost. The results provide the following findings about our model:

1. The system can reduce the stocks throughout the pipeline and remain service levels of retailers via investing in QR initiative.

2. The benefit from implementing $Q R$ is especially significant for a supply chain with high uncertainty in demand or the retailers requesting high service levels or incurring high carrying costs. 
3. The shipment cycle time will decrease after QR implemented. Additionally, the shipment cycle time is especially sensitive to the variation of manufacturer's production rate, the individual ordering cost, the variance of demand, and the retailer's carrying cost.

4. The decision of adopting QR is mainly influenced by the variance of demand and the retailer's service level threshold. The higher the demand uncertainty or the higher the retailer's service level threshold, the more beneficial to implement QR in supply chains.

\section{Appendix}

Let $G=\int_{S_{i}}^{\infty}\left(x-S_{i}\right) f\left(x_{i}\right) d x_{i}$ and $z_{i}=\frac{x_{i}-\mu_{i}}{\theta_{i}}$, where $f\left(x_{i}\right)$ represents a normal distribution with the mean $\mu_{i}$ and the standard deviation $\theta_{i}$. By replacing $x_{i}$ with $\mu_{i}+z_{i} \theta_{i}$, we have

$$
G=\int_{\frac{S_{i}-\mu_{i}}{\theta_{i}}}^{\infty}\left(\mu_{i}+z_{i} \theta_{i}-S_{i}\right) \phi\left(z_{i}\right) d z_{i}=\sigma_{i} \int_{\frac{S_{i}-\mu_{i}}{\theta_{i}}}^{\infty} z_{i} \phi\left(z_{i}\right) d z_{i}-\left(S_{i}-\mu_{i}\right) \int_{\frac{S_{i}-\mu_{i}}{\theta_{i}}}^{\infty} \phi\left(z_{i}\right) d z_{i},
$$

where $\phi\left(z_{i}\right)$ is the standard normal distribution and $\Phi\left(z_{i}\right)$ is the complementary cumulative normal distribution function defined as

$$
\Phi\left(z_{i}\right)=\int_{z_{i}}^{\infty} \phi(w) d w=\frac{1}{\sqrt{2 \pi}} \int_{z_{i}}^{\infty} e^{-\frac{w^{2}}{2}} d w .
$$

Let $v=\frac{z_{i}^{2}}{2}$, then there is $d v=z_{i} d z_{i}$ and

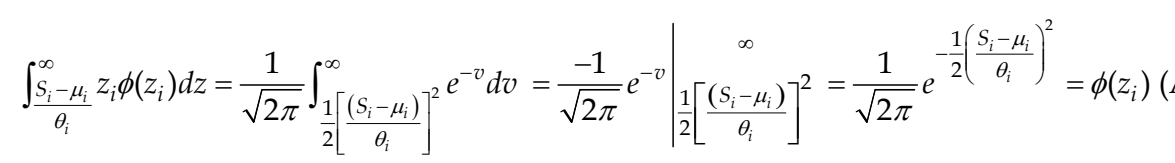

Next,

$$
\left(S_{i}-\mu_{i}\right) \int_{\frac{S_{i}-\mu_{i}}{\theta_{i}}}^{\infty} \phi\left(z_{i}\right) d z_{i}=\left(S_{i}-\mu_{i}\right) \Phi\left(z_{i}\right) .
$$

By substituting (A.2) and (A.3) into (A.1), we have

$$
G=\int_{S_{i}}^{\infty}\left(x-S_{i}\right) f\left(x_{i}\right) d x_{i}=\theta_{i} \phi\left(z_{i}\right)-\left(S_{i}-\mu_{i}\right) \Phi\left(z_{i}\right) .
$$

Let $\mu_{i}=D_{i}(T+l)$ and $\theta_{i}=\sigma_{i} \sqrt{T+l}$ and apply (A.4) to (3), (3) can be rewritten as

$$
1-\frac{\sigma_{i} \sqrt{T+l} \phi\left(z_{i}\right)-\left[S_{i}-D_{i}(T+l)\right] \Phi\left(z_{i}\right)}{D_{i}(T+l)} \geq a_{i}, i=1,2,3 .
$$

By substituting (1) in to (A.5) and rearranging the inequality, we have

$$
\phi\left(z_{i}\right)-z_{i} \Phi\left(z_{i}\right)-\left(1-\alpha_{i}\right) D_{i} \frac{\sqrt{T+l}}{\sigma_{i}} \leq 0, i=1,2,3 .
$$

This completes the proof for (5). Accordingly, (6) can be proved. 


\section{Acknowledgment}

This research was partially supported by the National Science Council, Taiwan ROC (Plan No. NSC 98-2410-H-415 -007).

\section{References}

Banerjee A (1986) A joint economic lot size model for purchaser and vendor. Decis Sci 17(3):92-311.

Banerjee A, Banerjee S (1992) Coordinated, orderless inventory replenishment for a single supplier and multiple buyers through electronic data interchange. Int J Technol Manage 79(4-5):328-336.

Banerjee A, Banerjee S (1994) A coordinated order-up-to inventory control policy for a single supplier and multiple buyers using electronic data interchange. Int J Prod Econ 35(1-3):85-91.

Ben-Daya M, Hariga M (2004) Integrated single vendor single buyer model with stochastic demand and variable lead time. Int J Prod Econ 92(1):75-80.

Ben-Daya M, Raouf A (1994) Inventory models involving lead time as a decision variable. J Oper Res Soc 45(5):579-582.

Chang HC, Ouyang LY, Wu KS, Ho CH (2006) Integrated vendor-buyer cooperative inventory models with controllable lead time and ordering cost reduction. Eur J Oper Res 170(2):481-495.

Chen FY, Krass D (2001) Inventory models with minimal service level constraints. Eur J Oper Res 134(1):120-140.

Chopra S, Meindl P (2007) Supply chain management. Pearson Education Inc., New Jersey.

EAN International (2000) Continuous replenishment: how to use the EAN.UCC standard. http://www.gs1.org/docs/EDI0002.pdf.

Goyal SK (1976) An integrated inventory model for a single-supplier-single- customer problem. Int J Prod Res 15:107-111.

Goyal SK (1988) A joint economic-lot-size model for purchaser and vendor: a comment. Decis Sci 19(1):236-241.

Goyal SK, Srinvasan G (1992) The individually responsible and rational comment. Decis Sci 23(3):777-784.

Liao CJ, Shyu CH (1991) An analytical determination of lead time with normal demand. Int J Oper Prod Manage 7(4):115-124.

Iyer AV, Bergen ME (1997) Quick response in manufacturer-retailer channels. Manage Sci 43(4):559-570.

Ouyang LY, Chuang BR (2000) Stochastic inventory model involving variable lead time with a service level. Yugosl J Oper Res 10(1):81-98.

Ouyang LY, Wu KS, Ho CH (2004) Integrated vendor-buyer cooperative models with stochastic demand in controllable lead time. Int J Prod Econ 92(3):255-266.

Ouyang LY, Wu, KS, Ho, CH (2007) An integrated vendor-buyer inventory model with quality improvement and lead time reduction. Int J Prod Econ 108(1-2):349-358.

Pan JC, Hsiao YC (2005) Integrated inventory models with controllable lead time and backorder discount consolidations. Int J Prod Econ 93-94:387-397.

Pan JC, Yang JS (2002) A study of an integrated inventory with controllable lead time. Int J Prod Res 40(5):1263-1273.

Taha HA (2002) Operations research: an introduction. Prentice Hall, Upper Sadle River, New Jersey. 


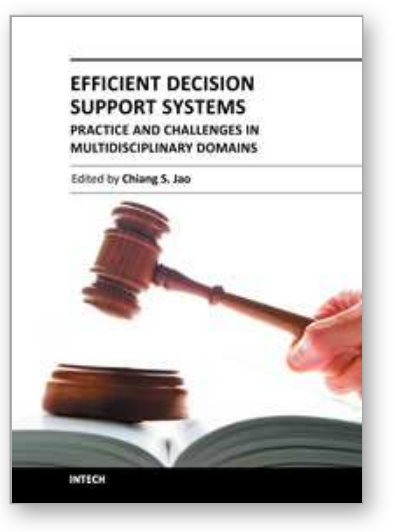

\author{
Efficient Decision Support Systems - Practice and Challenges in \\ Multidisciplinary Domains \\ Edited by Prof. Chiang Jao
}

ISBN 978-953-307-441-2

Hard cover, 478 pages

Publisher InTech

Published online 06, September, 2011

Published in print edition September, 2011

This series is directed to diverse managerial professionals who are leading the transformation of individual domains by using expert information and domain knowledge to drive decision support systems (DSSs). The series offers a broad range of subjects addressed in specific areas such as health care, business management, banking, agriculture, environmental improvement, natural resource and spatial management, aviation administration, and hybrid applications of information technology aimed to interdisciplinary issues. This book series is composed of three volumes: Volume 1 consists of general concepts and methodology of DSSs; Volume 2 consists of applications of DSSs in the biomedical domain; Volume 3 consists of hybrid applications of DSSs in multidisciplinary domains. The book is shaped decision support strategies in the new infrastructure that assists the readers in full use of the creative technology to manipulate input data and to transform information into useful decisions for decision makers.

\title{
How to reference
}

In order to correctly reference this scholarly work, feel free to copy and paste the following:

Shu-Lu Hsu and Chih-Ming Lee (2011). Quick Response in a Continuous-Replenishment-Programme Based Manufacturer Retailer Supply Chain, Efficient Decision Support Systems - Practice and Challenges in Multidisciplinary Domains, Prof. Chiang Jao (Ed.), ISBN: 978-953-307-441-2, InTech, Available from: http://www.intechopen.com/books/efficient-decision-support-systems-practice-and-challenges-inmultidisciplinary-domains/quick-response-in-a-continuous-replenishment-programme-based-manufacturerretailer-supply-chain

\section{INTECH}

open science | open minds

\section{InTech Europe}

University Campus STeP Ri

Slavka Krautzeka 83/A

51000 Rijeka, Croatia

Phone: +385 (51) 770447

Fax: +385 (51) 686166

www.intechopen.com

\section{InTech China}

Unit 405, Office Block, Hotel Equatorial Shanghai

No.65, Yan An Road (West), Shanghai, 200040, China 中国上海市延安西路65号上海国际贵都大饭店办公楼405单元

Phone: +86-21-62489820

Fax: +86-21-62489821 
(C) 2011 The Author(s). Licensee IntechOpen. This chapter is distributed under the terms of the Creative Commons Attribution-NonCommercialShareAlike-3.0 License, which permits use, distribution and reproduction for non-commercial purposes, provided the original is properly cited and derivative works building on this content are distributed under the same license. 